\title{
Cessation of targeted therapy after a complete response in BRAF-mutant advanced melanoma: a case series
}

\author{
Matteo S Carlino ${ }^{1,2,3,8}$, Vito Vanella ${ }^{4,8}$, Christina Girgis ${ }^{2}$, Diana Giannarelli ${ }^{5}$, Alex Guminski ${ }^{1,3,6}$, Lucia Festino ${ }^{4}$, \\ Richard F Kefford ${ }^{1,2,7}$, Alexander M Menzies ${ }^{1,3,6}$, Georgina V Long ${ }^{1,3,6}$ and Paolo A Ascierto ${ }^{\star 4}$ \\ ${ }^{1}$ Melanoma Institute Australia and The University of Sydney, Sydney, New South Wales, Australia; ${ }^{2}$ Crown Princess Mary Cancer \\ Centre Westmead, Sydney, New South Wales, Australia; ${ }^{3}$ University of Sydney, Sydney, New South Wales, Australia; ${ }^{4}$ Istituto \\ Nazionale per lo Studio e la Cura dei Tumori Fondazione 'G. Pascale', Via Mariano Semmola, 80131 Napoli, Italy; ${ }^{5}$ Regina Elena \\ National Cancer Institute, Rome, Italy; ${ }^{6}$ Royal North Shore Hospital, Sydney, New South Wales, Australia and ${ }^{7}$ Faculty of Medicine \\ and Health Sciences, Macquarie University, Sydney, New South Wales, Australia
}

Background: It is unknown whether melanoma patients achieving complete response (CR) with targeted therapy can safely discontinue treatment.

Methods: All patients treated with BRAF/MEK inhibitors achieving CR and ceasing treatment before progression were identified. Clinical data at treatment initiation, cessation and progression were examined.

Results: A total of 12 eligible patients were identified, with median follow-up of 16 months, of whom 6 (50\%) recurred at a median of 6.6 months after treatment cessation. One patient lost to follow-up until presentation with symptomatic recurrence was the only relapser to die. At relapse, the remaining five patients had an LDH $<1.2$ times ULN, four were ECOG 0 and one ECOG 1. Baseline characteristics and time to $C R$ and to discontinuation did not influence the rate of relapse.

Conclusions: A large proportion of patients achieving CR with BRAF/MEK inhibitors relapse after treatment cessation. The optimal treatment duration in such patients is unclear, particularly where alternative treatments are available.

The treatment of advanced melanoma has been revolutionised by the advent of immunotherapies inhibiting checkpoints on $\mathrm{T}$ cells (e.g., ipilimumab, nivolumab, pembrolizumab) (Hodi et al, 2010; Larkin et al, 2015; Robert et al, 2015) and inhibition of the mitogen-activated protein kinase (MAPK) pathway with BRAF inhibitors (vemurafenib, dabrafenib, encorafenib alone or in combination with MEK inhibitors (trametinib, cobimetinib)) in patients with BRAF V600-mutant melanoma (Chapman et al, 2011; Hauschild et al, 2012; Larkin et al, 2014; Long et al, 2014). Emerging data suggest that a subset of patients treated with BRAF/ MEK inhibitors survive beyond 3 years, and over 20\% are progression free at 3 years (Long et al, 2016). Furthermore, patients who achieved a complete response (CR) had a 3-year survival of $>60 \%$ (Long et al, 2016). Although patients who undergo a CR have a favourable survival, relapses while on treatment occur, with 2 of 7 patients relapsing in one recently published series (Menzies et al, 2015).

Unlike many immunotherapy studies, where treatment was continued for a finite period of time (unless there was progression or unacceptable toxicity), all studies of BRAF \pm MEK inhibitors continued treatment indefinitely (unless there was progression or unacceptable toxicity). The question of whether BRAF-targeted therapy should be continued until progression or whether it can be stopped at an earlier time point without the loss of benefit remains an unanswered question. Such considerations are clinically relevant given the impact that persistent low-grade toxicities can have

*Correspondence: Dr PA Ascierto; E-mail: p.ascierto@istitutotumori.na.it

${ }^{8}$ These authors contributed equally to this work.

Received 10 June 2016; revised 9 September 2016; accepted 19 September 2016; published online 6 October 2016

(c) 2016 Cancer Research UK. All rights reserved 0007 - 0920/16 
on patient quality of life and the potential risk of secondary malignancies due to paradoxical activation of the MAP kinase pathway with BRAF inhibitors (Menzies et al, 2013). Furthermore, indefinite treatment durations have health economic consequences.

Here we describe the outcomes of a case series of 12 patients who obtained a CR with a BRAF inhibitor alone or in combination with a MEK inhibitor, and subsequently ceased treatment.

\section{MATERIALS AND METHODS}

Patients with BRAF V600-mutant metastatic melanoma treated at three institutions, Melanoma Institute Australia and the Crown Princess Mary Cancer Centre Westmead Hospital, Sydney, Australia, and the National Cancer Institute, Naples, Italy, who achieved a CR after treatment with a BRAF inhibitor alone, or in combination with a MEK inhibitor, and ceased treatment for reasons other than disease progression were identified. The study was approved by individual institution ethics committees. Disease characteristics at the time of treatment initiation, and the timing and reasons for treatment cessation were recorded. In patients who relapsed, disease characteristics and response to subsequent therapy were documented. Progression-free survival (PFS) was determined using the Kaplan-Meier method.

\section{RESULTS}

Patients and treatment. From October 2009 to October 2015, 12 eligible patients were identified who had been enrolled in clinical trials or received $\mathrm{BRAF} \pm \mathrm{MEK}$ inhibitor treatment as part of an expanded access programme. Six patients were male and the median age was 49 years (range 29-62) (Table 1). In all, 10 (83\%) patients had BRAF V600E-mutant melanoma, 9 (75\%) had AJCC stage M1c disease and 11 (92\%) had normal LDH. Five (42\%) patients were treated with BRAF inhibitor monotherapy, whereas seven $(58 \%)$ patients started with a combination of dabrafenib and trametinib.

All patients stopped treatment because of toxicity, and one (patient 2) ceased treatment because of the diagnosis of a new RAS-mutant pancreatic cancer that was attributed to BRAF inhibitor-induced paradoxical MAPK pathway activation (Carlino et al, 2014).

Treatment outcomes. The median time from treatment initiation to $\mathrm{CR}$ was 6.5 months (range 1.6-18.6; Table 1 and Figure 1). The median duration of treatment in CR was 8 months. The median follow-up after treatment cessation was 16 months (range 2.959.5). From the time of treatment initiation the median PFS was 49.2 months, with the landmark 24-month PFS 64.8\%.

\section{Table 1. Patient characteristics}

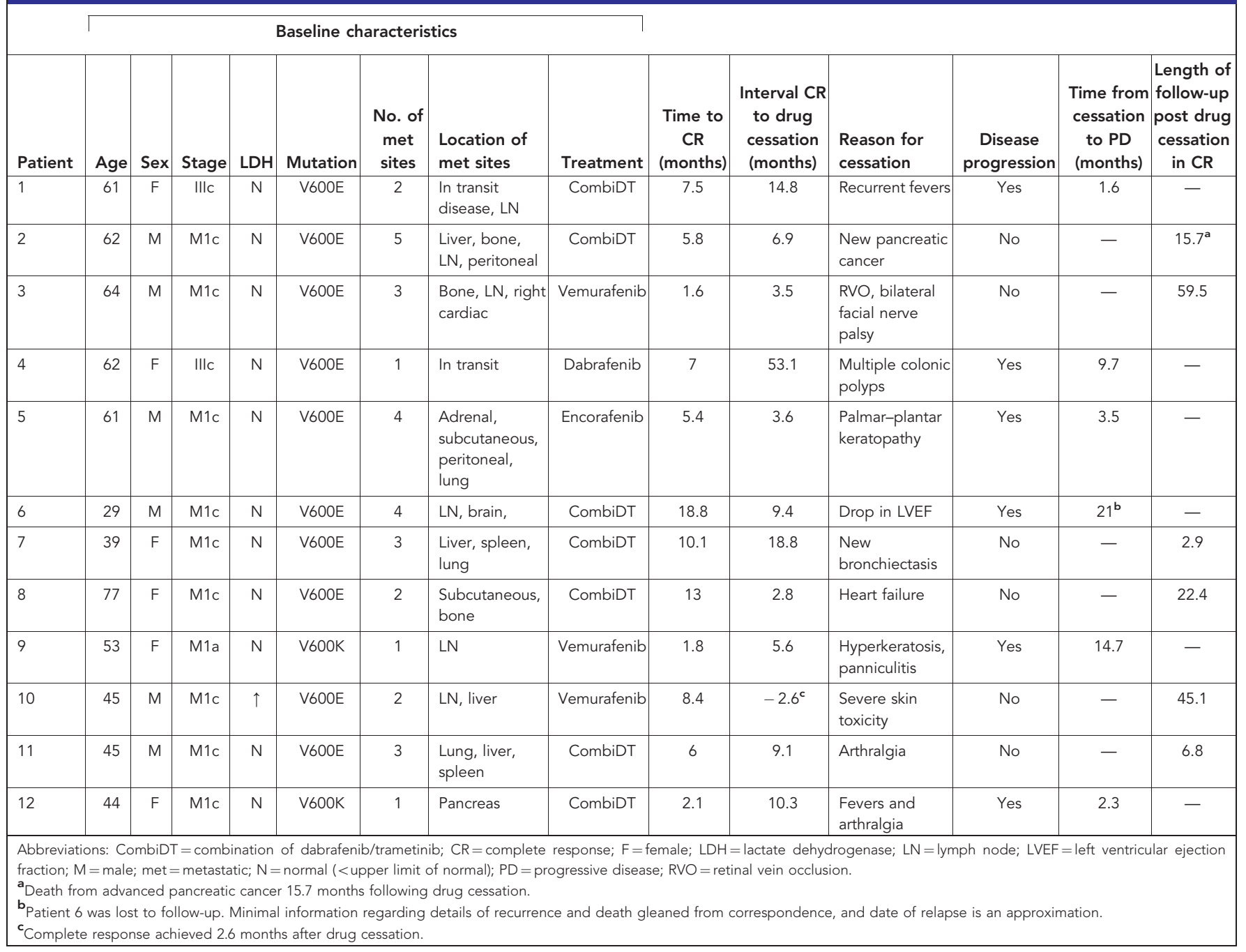


Patient characteristics at disease recurrence. Six patients (50\%) experienced disease recurrence after treatment cessation (Table 2 and Figure 1). In all of the patients who relapsed, disease recurred in original organ sites; three patients also developed metastasis in new organ sites (Table 2). One patient (patient 6) had refused follow-up before relapse, was not undergoing regular surveillance imaging and represented with symptomatic intracranial disease. Of the other five patients at relapse, four were ECOG 0 and the fifth was ECOG 1, and all had a normal or near normal LDH $(<1.2$ times upper limit of normal).

No clinical features either at the time of treatment commencement or cessation were associated with a subsequent relapse (Table 1). All patients who relapsed had a normal LDH at baseline. Furthermore, there was no difference in the time to CR, length of treatment or the treatment-related toxicities that led to cessation between those who relapsed and those who did not (Table 1).

The median time from treatment cessation to disease recurrence was 6.6 months (range 1.6-21 months). Of the six patients who relapsed, three subsequently received treatment with a combination of dabrafenib and trametinib, and two had a partial response (patients 4 and 9). The third patient was lost to follow-up (patient 6). The remaining three patients received immunotherapy (Table 2).

Two patients have died (Figure 1), the first from pancreatic cancer without evidence of melanoma recurrence (patient 2), and the second (patient 6) from melanoma at $\sim 8$ months after relapse.

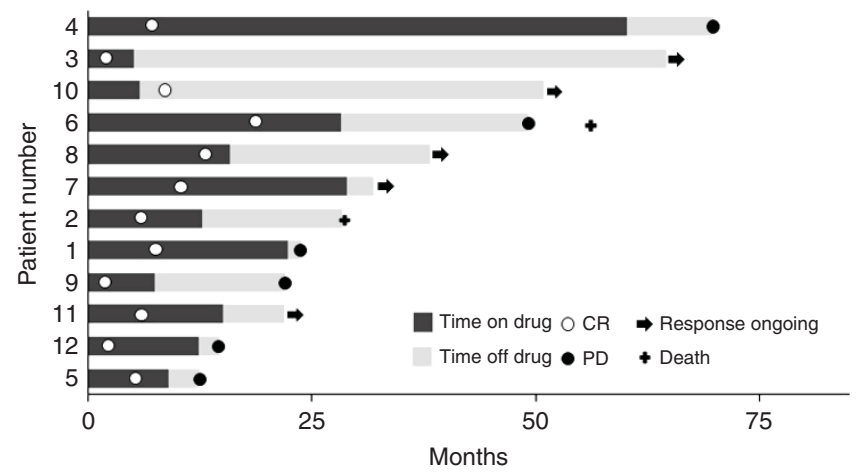

Figure 1. Patient treatment, response and progression timelines.

\section{DISCUSSION}

In this case series of patients with metastatic melanoma who achieved a CR and then ceased BRAF inhibitor-based therapy, we found that half subsequently relapsed, and there were no predictors for disease recurrence. All patients who were under regular clinical review with radiological surveillance were asymptomatic, or only had minor symptoms at relapse. The majority of patients had normal $\mathrm{LDH}$ at relapse, and all were suitable for subsequent therapy, including recommencing BRAF/MEK inhibitors with at least two of three responding.

A limitation of this study is the retrospective nature of the analysis, and the small cohort of patients under consideration. However, the multi-institutional experience may help overcome any bias from a single-centre analysis. Furthermore, the clinical characteristics and PFS of the patients included in this series are consistent with those who had undergone a CR in large international studies of dabrafenib in combination with trametinib (Long et al, 2016), suggesting this is a representative cohort. One important observation from our series is the absence of a correlation between duration of treatment and maintenance of response after that treatment was stopped. For example, one patient who stopped treatment after 5 months is disease free 59 months later. In contrast, another patient who received dabrafenib monotherapy for 60 months relapsed 9.7 months after treatment was stopped. Interestingly, one patient who received vemurafenib for 5.7 months obtained a best response 2.6 months after treatment cessation, and remains disease free with a follow-up of 44.5 months.

Two other publications have recently reported on the cessation of BRAF inhibitor treatment before progression. The first described three patients who experienced durable complete responses with BRAF inhibitor therapy that was then suspended because of toxicity; at a median follow-up of 15 months, none had relapsed. Of particular interest, all had previously been treated with interleukin-2 and ipilimumab (Wyluda et al, 2015). Consistent with our data, in a retrospective case series, half of the 12 patients who achieved a CR during treatment with a BRAF inhibitor remained disease free, with a median duration of follow-up after treatment discontinuation of 17 months (Tolk et al, 2015).

The rate of relapse seen in this and prior series is higher than what is seen with anti-PD1-treated melanoma. In the phase I study of pembrolizumab, 61 patients who achieved a CR stopped

Table 2. Patient demographics at relapse and response to subsequent therapy

\begin{tabular}{|c|c|c|c|c|c|c|c|c|c|}
\hline Patient & Treatment & $\begin{array}{l}\text { Time from } \\
\text { drug } \\
\text { cessation to } \\
\text { progression } \\
\text { (months) }\end{array}$ & $\begin{array}{c}\text { Site of } \\
\text { progression }\end{array}$ & $\begin{array}{c}\text { ECOG at } \\
\text { progression }\end{array}$ & $\begin{array}{c}\mathrm{LDH} \text { at } \\
\text { progression }\end{array}$ & $\begin{array}{l}\text { Subsequent } \\
\text { treatment }\end{array}$ & $\begin{array}{c}\text { Subsequent } \\
\text { response }\end{array}$ & $\begin{array}{l}\text { Length of } \\
\text { follow-up } \\
\text { post } \\
\text { subsequent } \\
\text { treatment } \\
\text { (months) }\end{array}$ & Outcome \\
\hline 1 & CombiDT & 1.6 & Old & 0 & $\mathrm{~N}$ & Ipilimumab & $\mathrm{SD}$ & 20.5 & Alive \\
\hline 4 & BRAFi & 9.7 & Old & 0 & $\mathrm{~N}$ & BRAFi/MEKi & PR & 3.2 & Alive \\
\hline 5 & BRAFi & 3.5 & Old and new & 0 & $1.2 \times U L N$ & $\begin{array}{l}\text { Ipilimumab and } \\
\text { pembrolizumab }\end{array}$ & $C R$ & 9 & Alive \\
\hline $6^{a}$ & CombiDT & $\sim 21$ & Old & Unknown & Unknown & BRAFi/MEKi & Unknown & $\sim 8$ & Died \\
\hline 9 & BRAFi & 14.7 & Old and new & 1 & $1.1 \times U L N$ & BRAFi/MEKi ${ }^{b}$ & PR & 23 & Alive \\
\hline 12 & CombiDT & 2.3 & Old and new & 0 & $\mathrm{~N}$ & Ipilimumabc & PD & 8.5 & Alive \\
\hline
\end{tabular}

Abbreviations: $\mathrm{BRAFi}=\mathrm{BRAF}$ inhibitor; CombiDT=combination of dabrafenib/trametinib; $\mathrm{CR}=$ complete response; $\mathrm{ECOG}=\mathrm{Eastern} \mathrm{Cooperative} \mathrm{Oncology} \mathrm{Group}$; $\mathrm{LDH}=$ lactate dehydrogenase; $\mathrm{MEKi}=\mathrm{MEK}$ inhibitor; $\mathrm{N}=$ normal; $\mathrm{PD}=$ progressive disease; $\mathrm{PR}=$ partial response; $\mathrm{SD}=$ stable disease; $\mathrm{ULN}=$ upper limit of normal.

a Patient 6 was lost to follow-up. Minimal information regarding details of recurrence and death gleaned from correspondence, and date of relapse is an approximation.

b Patient 9 was subsequently treated with ipilimumab and then nivolumab.

${ }^{c}$ Patient 12 was subsequently treated with pembrolizumab. 
therapy. After a median of 10 months off treatment, only two patients (3\%) had progressed (Robert et al, 2016).

One hypothesis for disease recurrence after a CR and cessation of treatment may be that micrometastatic disease remains under cytostatic control during treatment, and after treatment cessation this subclinical disease is then able to proliferate. In preclinical models, genetic alterations other than BRAF mutations, such as PTEN loss, are associated with an inability of BRAF inhibitors to induce apoptosis while maintaining their cytostatic effect (Paraiso et al, 2011). Interpatient heterogeneity of such variables may explain why only a subset of patients relapse. An alternative hypothesis is that immune mechanisms have played a role in those patients who have not recurred (Klein et al, 2013).

The impact of cessation of kinase inhibitors has also been examined in other malignancies. In advanced gastrointestinal stromal tumours (GISTs), the cessation of imatinib, even in patients without residual disease, leads to rapid disease recurrence (Blay et al, 2007). Moreover, the data regarding the need for ongoing treatment with trastuzumab in HER-2-amplified metastatic breast cancer are limited and conflicted, with both relapses and prolonged responses seen (Beda et al, 2007; Gullo et al, 2012). Trastuzumab-treated breast cancer may rely on immunological mechanisms via antibody-dependent cell toxicity, not possible with small-molecule inhibitors (Collins et al, 2012).

The patients presented here differ from those described with GIST in that the time from treatment cessation to relapse varied from $<2$ months to almost 2 years, suggesting treatment cessation does not result in a rapid expansion of subclinical disease. Given this, it is unknown whether the cessation of treatment increases the likelihood of disease recurrence, as compared with patients in CR who continue treatment, as relapses do occur in patients who have undergone a CR while remaining on treatment (Menzies et al, 2015; Long et al, 2016).

The data presented here may have implications for the potential adjuvant use of BRAF and MEK inhibitors in BRAF-mutant melanoma. In GISTs treated with adjuvant imatinib, an increased rate of recurrences are seen soon after cessation of treatment (Joensuu et al, 2012). Two adjuvant studies in BRAF V600-mutant melanoma (BRIM-8 (NCT01667419) and COMBI-AD (NCT01682083)) have completed accrual and results are awaited. In both studies patients received 12 months of vemurafenib or dabrafenib/trametinib or placebo, respectively. It remains to be determined whether adjuvant $\mathrm{BRAF/MEK}$ inhibition will prevent relapse and be associated with an improved overall survival or only delay relapse with benefit limited to an improvement in relapse- free survival only.

A significant proportion of patients ( $50 \%$ in our case series) who obtain a $\mathrm{CR}$ on $\mathrm{BRAF} \pm$ MEK inhibitor therapy have continued prolonged response after cessation. Based on the available data in this and other series, predicting those who will obtain long-term benefit $v s$ those who will relapse is not possible. Prospective randomised discontinuation clinical trials with added translational end points may answer the question of who can safely cease treatment. However, recruitment to such a study would be difficult in the current treatment landscape of melanoma. The data presented in this case series should assist clinicians and their patients to make individualised decisions, and patients should remain on treatment until progression or unacceptable toxicity. Importantly the clinical behaviour of all patients who relapsed while undergoing close surveillance including regular imaging suggests treatment interruption is unlikely to be associated with rapid progression leading to death without the ability to institute subsequent treatment.

\section{CONFLICT OF INTEREST}

MS Carlino participated in the advisory boards for Merck, Amgen, Novartis and Bristol Myer Squibb. AM Menzies participated in the advisory boards for Merck, Novartis and Bristol Myer Squibb. RF Kefford participated in the advisory boards for Merck, Amgen, Novartis and Bristol Myer Squibb. GV Long participated in the advisory boards of Amgen, Bristol Myer Squibb, Glaxosmithkline, Novartis, Provectus, Roche and Merck Inc. PA Ascierto participated in the advisory boards for Merck, Amgen, Novartis and Bristol Myer Squibb. The remaining authors declare no conflict of interest.

\section{REFERENCES}

Beda M, Basso U, Ghiotto C, Monfardini S (2007) When should trastuzumab be stopped after achieving complete response in HER2-positive metastatic breast cancer patients? Tumori 93(5): 491-492.

Blay JY, Le Cesne A, Ray-Coquard I, Bui B, Duffaud F, Delbaldo C, Adenis A, Viens P, Rios M, Bompas E, Cupissol D, Guillemet C, Kerbrat P, Fayette J, Chabaud S, Berthaud P, Perol D (2007) Prospective multicentric randomized phase III study of imatinib in patients with advanced gastrointestinal stromal tumors comparing interruption versus continuation of treatment beyond 1 year: the French Sarcoma Group J Clin Oncol 25(9): 1107-1113.

Carlino MS, Kwan V, Miller DK, Saunders CA, Yip D, Nagrial AM, Tomlinson J, Grimmond SM, Scolyer RA, Kefford RF, Biankin AV, Long GV (2014) New RAS-mutant pancreatic adenocarcinoma with combined BRAF and MEK inhibition for metastatic melanoma. J Clin Oncol 33: e52-e56.

Chapman PB, Hauschild A, Robert C, Haanen JB, Ascierto P, Larkin J, Dummer R, Garbe C, Testori A, Maio M, Hogg D, Lorigan P, Lebbe C, Jouary T, Schadendorf D, Ribas A, O’Day SJ, Sosman JA, Kirkwood JM, Eggermont AM, Dreno B, Nolop K, Li J, Nelson B, Hou J, Lee RJ, Flaherty KT, McArthur GA. BRIM-3 Study Group (2011) Improved survival with vemurafenib in melanoma with BRAF V600E mutation. $N$ Engl J Med 364(26): 2507-2516.

Collins DM, O’Donovan N, McGowan PM, O'Sullivan F, Duffy MJ, Crown J (2012) Trastuzumab induces antibody-dependent cell-mediated cytotoxicity (ADCC) in HER-2-non-amplified breast cancer cell lines. Ann Oncol 23(7): 1788-1795.

Gullo G, Zuradelli M, Sclafani F, Santoro A, Crown J (2012) Durable complete response following chemotherapy and trastuzumab for metastatic HER2positive breast cancer. Ann Oncol 23(8): 2204-2205.

Hauschild A, Grob JJ, Demidov LV, Jouary T, Gutzmer R, Millward M, Rutkowski P, Blank CU, Miller Jr WH, Kaempgen E, Martin-Algarra S, Karaszewska B, Mauch C, Chiarion-Sileni V, Martin AM, Swann S, Haney P, Mirakhur B, Guckert ME, Goodman V, Chapman PB (2012) Dabrafenib in BRAF-mutated metastatic melanoma: a multicentre, open-label, phase 3 randomised controlled trial. Lancet 380(9839): 358-365.

Hodi FS, O’Day SJ, McDermott DF, Weber RW, Sosman JA, Haanen JB, Gonzalez R, Robert C, Schadendorf D, Hassel JC, Akerley W, van den Eertwegh AJ, Lutzky J, Lorigan P, Vaubel JM, Linette GP, Hogg D, Ottensmeier CH, Lebbe C, Peschel C, Quirt I, Clark JI, Wolchok JD, Weber JS, Tian J, Yellin MJ, Nichol GM, Hoos A, Urba WJ (2010) Improved survival with ipilimumab in patients with metastatic melanoma. $N$ Engl J Med 363(8): 711-723.

Joensuu H, Eriksson M, Sundby Hall K, Hartmann JT, Pink D, Schutte J, Ramadori G, Hohenberger P, Duyster J, Al-Batran SE, Schlemmer M, Bauer S, Wardelmann E, Sarlomo-Rikala M, Nilsson B, Sihto H, Monge OR, Bono P, Kallio R, Vehtari A, Leinonen M, Alvegard T, Reichardt P (2012) One vs three years of adjuvant imatinib for operable gastrointestinal stromal tumor: a randomized trial. JAMA 307(12): 1265-1272.

Klein O, Ribas A, Chmielowski B, Walker G, Clements A, Long GV, Kefford RF (2013) Facial palsy as a side effect of vemurafenib treatment in patients with metastatic melanoma. J Clin Oncol 31(12): e215-e217.

Larkin J, Ascierto PA, Dreno B, Atkinson V, Liszkay G, Maio M, Mandala M, Demidov L, Stroyakovskiy D, Thomas L, de la Cruz-Merino L, Dutriaux C, Garbe C, Sovak MA, Chang I, Choong N, Hack SP, McArthur GA, Ribas A (2014) Combined vemurafenib and cobimetinib in BRAF-mutated melanoma. N Engl J Med 371(20): 1867-1876.

Larkin J, Chiarion-Sileni V, Gonzalez R, Grob JJ, Cowey CL, Lao CD, Schadendorf D, Dummer R, Smylie M, Rutkowski P, Ferrucci PF, Hill A, 
Wagstaff J, Carlino MS, Haanen JB, Maio M, Marquez-Rodas I, McArthur GA, Ascierto PA, Long GV, Callahan MK, Postow MA, Grossmann K, Sznol M, Dreno B, Bastholt L, Yang A, Rollin LM, Horak C, Hodi FS, Wolchok JD (2015) Combined nivolumab and ipilimumab or monotherapy in untreated melanoma. $N$ Engl J Med 373(1): 23-34.

Long GV, Stroyakovskiy D, Gogas H, Levchenko E, de Braud F, Larkin J, Garbe C, Jouary T, Hauschild A, Grob JJ, Chiarion Sileni V, Lebbe C, Mandala M, Millward M, Arance A, Bondarenko I, Haanen JB, Hansson J, Utikal J, Ferraresi V, Kovalenko N, Mohr P, Probachai V, Schadendorf D, Nathan P, Robert C, Ribas A, DeMarini DJ, Irani JG, Casey M, Ouellet D, Martin AM, Le N, Patel K, Flaherty K (2014) Combined BRAF and MEK inhibition versus BRAF inhibition alone in melanoma. $N$ Engl J Med 371(20): 1877-1888.

Long GV, Weber JS, Infante JR, Kim KB, Daud A, Gonzalez R, Sosman JA, Hamid O, Schuchter L, Cebon J, Kefford RF, Lawrence D, Kudchadkar R, Burris 3rd HA, Falchook GS, Algazi A, Lewis K, Puzanov I, Ibrahim N, Sun P, Cunningham E, Kline AS, Del Buono H, McDowell DO, Patel K, Flaherty KT (2016) Overall survival and durable responses in patients with BRAF V600-mutant metastatic melanoma receiving dabrafenib combined with trametinib. J Clin Oncol 34(8): 871-878.

Menzies AM, Kefford RF, Long GV (2013) Paradoxical oncogenesis: are all BRAF inhibitors equal? Pigment Cell Melanoma Res 26(5): 611-615.

Menzies AM, Wilmott JS, Drummond M, Lo S, Lyle M, Chan MM, Thompson JF, Guminski A, Carlino MS, Scolyer RA, Kefford RF, Long GV (2015) Clinicopathologic features associated with efficacy and long-term survival in metastatic melanoma patients treated with BRAF or combined BRAF and MEK inhibitors. Cancer 121(21): 3826-3835.

Paraiso KHT, Xiang Y, Rebecca VW, Abel EV, Chen YA, Munko AC, Wood E, Fedorenko IV, Sondak VK, Anderson ARA, Ribas A, Dalla Palma M,
Nathanson KL, Koomen JM, Messina JL, Smalley KSM (2011) PTEN loss confers BRAF inhibitor resistance to melanoma cells through the suppression of BIM expression. Cancer Res 71(7): 2750-2760.

Robert C, Ribas A, Hamid O, Daud A, Wolchok JD, Joshua AM, Hwu W-J, Weber JS, Gangadhar TC, Joseph RW, Dronca RS, Patnaik A, Zarour HM, Kefford R, Hersey P, Li X, Diede SJ, Ebbinghaus S, Hodi FS (2016) Threeyear overall survival for patients with advanced melanoma treated with pembrolizumab in KEYNOTE-001. J Clin Oncol (suppl; abstr 9503).

Robert C, Schachter J, Long GV, Arance A, Grob JJ, Mortier L, Daud A, Carlino MS, McNeil C, Lotem M, Larkin J, Lorigan P, Neyns B, Blank CU, Hamid O, Mateus C, Shapira-Frommer R, Kosh M, Zhou H, Ibrahim N, Ebbinghaus S, Ribas A. KEYNOTE-006 investigators (2015)

Pembrolizumab versus ipilimumab in advanced melanoma. N Engl J Med 372(26): 2521-2532.

Tolk H, Satzger I, Mohr P, Zimmer L, Weide B, Schad S, Gutzmer R (2015) Complete remission of metastatic melanoma upon BRAF inhibitor treatment - what happens after discontinuation? Melanoma Res 25(4): 362-366.

Wyluda EJ, Cheng J, Schell TD, Haley JS, Mallon C, Neves RI, Robertson G, Sivik J, Mackley H, Talamo G, Drabick JJ (2015) Durable complete responses off all treatment in patients with metastatic malignant melanoma after sequential immunotherapy followed by a finite course of BRAF inhibitor therapy. Cancer Biol Ther 16(5): 662-670.

This work is published under the standard license to publish agreement. After 12 months the work will become freely available and the license terms will switch to a Creative Commons AttributionNonCommercial-Share Alike 4.0 Unported License. 